\title{
O Projeto Segurança Presente e a Militarização do Espaço Urbano do Rio de Janeiro
}

The Segurança Presente Project and the Militarization of the Urban Space of Rio de Janeiro

Le projet Segurança Presente et la militarisation de l'espace urbain de Rio de Janeiro El proyecto Segurança Presente y la militarización del espacio urbano de Río de Janeiro

\section{Thiago Sardinha}

\section{CpenEdition}

Journals

Edição electrónica

URL: http://journals.openedition.org/espacoeconomia/18043

DOI: 10.4000/espacoeconomia. 18043

ISSN: 2317-7837

Editora

Núcleo de Pesquisa Espaço \& Economia

Refêrencia eletrónica

Thiago Sardinha, «O Projeto Segurança Presente e a Militarização do Espaço Urbano do Rio de Janeiro», Espaço e Economia [Online], 20 | 2020, posto online no dia 28 dezembro 2020, consultado o 29 janeiro 2021. URL: http://journals.openedition.org/espacoeconomia/18043 ; DOI: https://doi.org/ 10.4000/espacoeconomia.18043

Este documento foi criado de forma automática no dia 29 janeiro 2021.

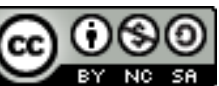

Espaço e Economia - Revista brasileira de geografia econômica est mise à disposition selon les termes de la licence Creative Commons Attribution - Pas d'Utilisation Commerciale - Partage dans les Mêmes Conditions 4.0 International. 


\section{O Projeto Segurança Presente e a Militarização do Espaço Urbano do Rio de Janeiro}

The Segurança Presente Project and the Militarization of the Urban Space of Rio de Janeiro

Le projet Segurança Presente et la militarisation de l'espace urbain de Rio de Janeiro El proyecto Segurança Presente y la militarización del espacio urbano de Río de Janeiro

\section{Thiago Sardinha}

\section{Introdução}

A militarização do espaço urbano ou, como alguns preferem, militarização da vida social, o que em termos epistemológicos possuem o mesmo significado, avança de maneira intensa, isto é, a disciplina militar, suas regras de convívio e tratamento social viraram um espécie de modelo social generalizado impactando a vida urbana, principalmente quando atinge ao grupos armados e a esfera institucional da segurança pública. Nesse sentido, podemos definir a militarização do espaço urbano como o controle rigoroso, amarado e ostensivo com domínio territorial recorrendo às práticas militares com uso da violência direta direcionada aos sujeitos indesejáveis da cidade ${ }^{1}$. Esta intensificação está diretamente associada à crise urbana e social provocada pela crise capitalista que se aprofunda levando toda a sociedade ao colapso social. Várias e expressões medidas de cunho militar estão sendo tomadas tanto no Brasil ${ }^{2}$ quanto em outros países como tentativas de administrar esta crise e manter em funcionamento o que ainda persiste nas mofadas relações sociais burguesas. Sendo assim, o projeto Segurança Presente, aplicado em alguns bairros na cidade do Rio de Janeiro e na região metropolitana é uma expressão do avanço do processo de militarização no espaço urbano, porém, com 
contornos temerosos merecedores de uma análise cuidadosa. Para tanto realizaremos pontes teóricas com as reflexões de alguns autores que tratam da temática, dentre eles Stephen Graham de "Cidades Sitiadas e o Novo Urbanismo Militar."

Por muito tempo a militarização do espaço urbano era vista apenas em momentos pontuais decorrente do uso das Forças Armadas para realizar o policiamento na cidade no lugar da polícia militar e restrita unicamente ao campo institucional, é por isso que estou convencido que a militarização do espaço urbano extrapola a esfera institucional. Não obstante, estas intervenções eram sempre convocadas em momentos de crise aguda e aumento da criminalidade como roubos, furtos e homicídios. Seu objetivo era ocupar as ruas da cidade com todo seu aparato de guerra para assim retomar a calmaria ameaçada pelas classes perigosas. As classes perigosas ou dangerous classes, segundo Guimarães (1982), representa um conjunto social formado à margem da sociedade civil e surgiu na primeira metade do século XIX, num período em que a superpopulação relativa ou o exército industrial de reserva atingia proporções exponenciais na Inglaterra. As classes perigosas eram formadas por pessoas que tivessem passagem pela prisão ou não, notoriamente pessoas que dependiam da pilhagem, roubos e trapaças, convencidas de que poderiam, para o seu sustento e o de sua família, ganhar mais praticando furtos do que trabalhando.

\section{Crise do Capitalismo e a Militarização do Espaço Urbano}

3 No capitalismo contemporâneo é possível apontar a maneira como se constitui as classes perigosas: 1) pelo conjunto populacional sobrante e excludente que forma uma força de trabalho dispensada do processo produtivo direto, tanto pelo avanço tecnológico quanto pela reorganização da atividade produtiva e até mesmo pela generalização do exército industrial de reserva; 2) pelo contingente de pessoas submetidas ao subemprego e ao emprego precário, sem qualquer seguridade social e trabalhista; 3) a população negra da cidade que ocupa as favelas e periferias. Este último ponto vai de encontro com a análise de Wacquant (2006) sobre a "estigmatização territorial da marginalidade avançada". Loic Wacquant, sociólogo francês, assegura que os Estados Unidos e nos principais países da Europa, vivenciam um novo regime de marginalidade como consequências das novas formas de pobreza na sociedade contemporânea. Estas novas formas não são mais cíclicas ou temporárias, mas sim, estruturais. São transformações, portanto, originárias da crise estrutural do capitalismo. Para Wacquant, a marginalidade avançada explica como diferente de processos anteriores, as novas formas de pobreza urbana, acompanhadas de uma estigmatização territorial, são consequências da decomposição de classe possuindo uma dupla tendência para a precarização do trabalho e o direcionamento para territórios inferiores do espaço social urbano.

4 Se aproximarmos a discussão trazida por Loic Wacquant com o excelente trabalho de Michelle Alexander acerca da "Nova Segregação: racismo e encarceramento em massa" é possível aproveitar a análise de Wacquant para extrair uma dimensão racial e racista do fenômeno e até mesmo a passagem do território estigmatizado para a prisão e estabelecer um diálogo entre os (as) autores. Michelle Alexander aponta o papel de mecanismos jurídicos, como o Jim Crow, e mais a chamada Guerra às Drogas como sendo fundamentais para o aumento punitivo através do encarceramento em massa da 
população negra e inserida em uma realidade de decadência econômica e penúria social, população ocupante do território estigmatizado mencionado por Wacquant.

Em menos de trinta anos a população carcerária dos Estados Unidos explodiu: de 300 mil, passou para mais de 2 milhões - e as condenações ligadas às drogas foram responsáveis pela maior parte desse aumento. A dimensão racial do encarceramento em massa é sua característica mais impressionante. Nenhum outro país no mundo aprisiona tanto minorias raciais. Os Estados Unidos prendem um percentual maior da sua população negra do que a África do Sul na época do apartheid (ALEXANDER, 2014 p.42).

5 Este ponto é crucial, pois explica como a estrutura social dominante utiliza-se de diferentes mecanismos históricos para a manutenção de um projeto social pretendido universal de maneira que aqueles que não fazem parte ou se negam a esta universalidade são as maiores vítimas, a militarização é um deles. A reflexão de Michelle Alexander ratifica-se quando afirma que a vida dos negros/as norteamericanos passou significar uma predisposição racial para serem escravos, segregados e mesmo encarcerados. Alinha-se muito com o que Mbembe afirma em a "Critica da Razão Negra" de como o racismo cumpriu (e cumpre) um papel de definição do outro num conceito filosófico, moderno e colonizador universalizante.

A raça é o que permite identificar e definir grupos populacionais em função dos riscos diferenciados e mais ou menos aleatórios dos quais cada um deles seria o vetor. Nesse contexto, os processos de racialização têm como objetivo marcar [violentamente] esses grupos populacionais, fixar o mais precisamente possível os limites em que podem circular, determinar o mais exatamente possível os espaços que podem ocupar, em suma, assegurar que a circulação se faça num sentido que afaste quaisquer ameaças e garanta a segurança geral. Trata-se de fazer a triagem desses grupos populacionais, marcá-los simultaneamente como espécies, séries e casos, dentro de um cálculo geral de risco, do acaso e das probabilidades, de maneira a poder prevenir perigos inerentes à sua circulação e, se possível, neutralizá-los antecipadamente, no mais das vezes por meio da imobilidade, do encarceramento [extermínio] ou deportação. A raça, desse ponto de vista, funciona como um dispositivo de segurança fundado naquilo que poderíamos chamar de princípio do enraizamento biológico pela espécie. A raça [o racismo] é ao mesmo tempo ideologia e tecnologia de governos [e da estrutura social] ( p. 74-75).

6 Se aprofundarmos ainda mais os mecanismos de controle social generalizado dos perfis estereotipados no caso brasileiro, observa-se um cenário exponencialmente dramático e horrendo provocado por este arranjo social violento e militarizante. Por isso que concordo com o professor Marildo Menegat ao afirmar que a atual situação social capitalista brasileira reflete o fim da gestão da barbárie que já vem desde a última grande crise na década de 1970. Portanto, não há para onde fugir, não existem quaisquer medidas compensatórias que tentam aliviar o pauperismo estrutural, a barbárie burguesa expõe a nu o modo de destruição da vida social. Não se consegue mais combinar operações policiais em favelas com acesso ao crédito e consumo dos pobres que conjunturalmente saíram da linha da extrema pobreza durante um breve período. Portanto, resta a estes a exposição vulnerável a uma ordem violenta e militarizada produtora de "sujeitos matáveis".

O colapso da sociedade brasileira entrou num tempo de aceleração. Uma economia politica da barbárie e consolidou e é ela que explica os movimentos de alterações dos direitos trabalhistas, das aposentadorias, do teto de gastos e, inclusive, do campo de conduta dos indivíduos cuja liberdade de escolha dos diretos humanos tentavam preservar. Esta nova intencionalidade, mais crua e brutal, precisa ser entendida para além de simples maniqueísmos políticos, pois, ao que tudo indica, 
nunca esteve ausente no período anterior que por ora findou (MENEGAT, 2019, p.

118).

7 É interessante, também, adentrar brevemente antes de dar continuidade na reflexão inicial, mas que se faz necessário neste instante, nos aspectos institucional e legal da militarização em território nacional e no âmbito constitucional. Em 1988, foi promulgado 245 artigos, sobre intervenções militares e uso das Forças Armadas para policiamento urbano. Plano associando com as mais avançadas democracias do mundo. Na esteira destes preceitos, no entanto, uma parte significativa da Constituição de 1998 permaneceu intacta herdando a Constituição do período militar de 1967 e à sua emenda de 1969, estas aproximam-se das cláusulas relacionadas as Forças Armadas, Policias Militares estaduais, Sistema Judiciário Militar e de Segurança Pública em geral. As Forças Armadas sabiam da importância de perpetuarem o longo continuísmo ativo de suas práticas, mesmo abrindo o país para uma democracia, nesse sentido, nomearam 13 oficiais superiores para fazer lobby representando os interesses militares diante dos constituintes civis.

8 Para a construção da chamada Constituição Cidadã de 1988, os trabalhos tiveram que ser divididos em comissões e subcomissões, e foi aí que os militares tiveram um papel decisivo. A Comissão de Sistematização a presidência era do deputado Bernado Cabral (PMDB, PFL e PP), um notório aliado dos militares e que depois seria Ministro da Justiça de Fernando Collor. Já a Comissão de Organização Eleitoral Partidária e Garantia das Instituições, que ficou a cargo dos capítulos ligados às Forças Armadas e a Segurança Pública, era presidida pelo senador Jarbas Passarinho (ARENA, PPB, PDS, PPR e PP), um coronel da reserva que serviu como ministro dos governos de Costa e Silva, Médici e Figueiredo. Também foi um dos que assinou, em 1968, o Ato institucional número 5 $(\mathrm{AI}-5)^{3}$.

Ricardo Fiúza foi um militante fervoroso contra o impedimento do controle do Exército sobre as Policias Militares, optando pela autonomia das Forças Armadas. Na prática o que Fiúza desejava era que o Exército tivesse o controle sobre as PM's, justificando que o governo em algum momento precisaria de todas as forças para controlar contestadores da ordem social. Nas reuniões desta subcomissão presidida por Ricardo Fiúza participaram 28 pessoas originarias das diferentes esferas das Forças Armadas, facilitando a manutenção constitucional dos interesses militares.

10 Foi neste contexto que o artigo 142 da constituição brasileira decidiria que as Forças Armadas se preocupariam com a defesa da pátria, à garantia dos poderes constitucionais e, da lei e da ordem. Na prática, são os militares que possuem o poder de funcionamento das outras esferas do Estado como: Legislativo, Executivo e Judiciário. Portanto, fica claro que as Forças Armadas garantem uma democracia que elas mesmas definiram como democracia! Ignora-se completamente a Presidência e o Congresso Nacional. Entretanto, o artigo não define quem e nem quando as ordens foram violadas, ou seja, virou uma espécie de bravata incontestável que fundamentaria ações violentas seguidas de morte daqueles que o exército definiu como desordeiros.

11 artigo 142 também deferiu que tanto o Judiciário quanto o Congresso poderiam pedir a intervenção das Forças Armadas em assuntos domésticos, leia-se contra o seu inimigo interno. Tal fato permitiu que um Juiz de Volta Redonda convocasse o Exército para intervir numa ocupação grevista na CSN (Companhia Siderúrgica Nacional) em 1988, causando a morte de três operários. De lá para cá, foram inúmeras as intervenções das Forças Armadas principalmente para ações/ocupações em favelas com objetivo de 
retomar a sensação de segurança abalada pelo aumento da violência no Brasil e principalmente na cidade do Rio de Janeiro, como se a favela fosse a "fábrica de violência". Essa é a única justificativa possível para o uso das Forças Armadas no Brasil, enquanto não ocorre ameaça de invasão externa nas fronteiras do Estado Nação, Exército, Marinha e Aeronáutica aplicam todo treinamento e capacidade bélica de guerra para fazer policiamento nas cidades.

No entanto, o aspecto institucional da militarização do espaço urbano não circunscreve apenas nos marcos legais da institucionalidade da qual estou discutindo aqui, pelo contrário, ultrapassa abertamente, infiltrando-se na vida social de maneira geral e muita das vezes sendo substituída para resolver questões sociais como é o caso das escolas e seus projetos pedagógicos, manifestações culturais, serviços, etc. Por tudo isso é que afirmo ser a militarização do espaço urbano o resultado de uma forma social em ruínas.

13 A militarização do espaço urbano pode ser entendida também como um conjunto de medidas e, sobretudo da atuação de diferentes atores no espaço urbano. Medidas militarizadas para problemas sociais característicos da cidade, como a pobreza e a miríade das desigualdades sociais envolvendo tanto o Estado como grupos armados. Portanto, assim como em Bagdá, Porto Príncipe, Michoacán, Medelín, e algumas cidades norte americanas como Manhattan, Charlotte, Carolina do Norte, etc. A cidade do Rio de Janeiro vem experimentando, já algum tempo, este novo urbanismo militarizado em que modifica substancialmente a estrutura física das cidades nos seus planos políticos e sociais ou simbólicos.

Esses planos de reestruturação das cidades formaram esses caminhos desde o fim da Guerra Fria. Neste período as tensões militares estavam quase sempre distantes das cidades, restritas a fronteiras territoriais dos países em disputa. Entretanto, com o mundo cada vez mais urbanizado, as tensões militares são deslocadas para dentro dos próprios países, no centro de suas principais cidades, ou seja, deixam de ser algo distante da população citadina para tornar-se mais um ente no seu cotidiano. Um fato significativo presente nesta trama mutável é: a transferência de um aparato bélico bastante sofisticado utilizado em guerras pelas forças de segurança que atuavam no estrangeiro para a dominação completa de ambientes urbanos, tecnologias usadas na Guerra Fria, por exemplo, recebem garantias de uso generalizado em espaços urbanos domésticos. Stephen Graham afirma que este urbanismo militar materializa a discussão que Foucault realizou sobre o "bumerangue" em que instituições, armas e técnicas militarizadas de exercício de poder aplicadas nas colônias, seriam também aplicadas nas metrópoles, ou seja, voltariam para os colonos ocidentais, sendo utilizadas no policiamento urbano.

O novo urbanismo militar se alimenta de experiências com estilos de objetivo e tecnologia em zona de guerras coloniais, como Gaza ou Bagdá, ou operações de segurança em eventos esportivos ou cúpulas policiais internacionais. Essas operações funcionam como um teste para tecnologia e as técnicas a serem vendidas pelos prósperos mercados de segurança nacional ao redor do mundo. Por processos de imitação, modelos explicitamente coloniais de pacificação, militarização e controle, aperfeiçoados nas ruas do Sul do globo, se espalham pelas cidades do centro capitalistas do Norte (GRAHAM, 2012, p. 30).

O que Stephen Graham está dizendo é que armas de ponta e técnicas voltadas para guerras são testadas e utilizadas em cidades em conflito declarado e depois são aplicadas em cidades dos países que as fabricaram ou mesmo que estão ocupando 
militarmente os territórios "testes". Na verdade, mesmo que sejam desenvolvidas para este fim, em que posteriormente "retornem" para os países do centro capitalista, estas técnicas e armas ganham um amplo mercado, assumindo um amplo uso em locais anteriormente desconsiderados. Portanto, este esforço traduz-se em um controle estendido do cotidiano da sociedade civil, seja no centro ou na periferia do capitalismo, há uma importante mudança espacial a partir de escalas necessárias para manutenção do controle.

16 Nesta dinâmica, mistura-se Forças Policias, Forças Armadas e Grupos Armados movimentando no entorno desses atores todo aparato bélico possível. São circuitos militarizados que se fundem de tal maneira dificultando o entendimento de outrora em que era possível compreender com clareza onde tais forças eram utilizadas de acordo com o potencial bélico do inimigo. Mais recentemente, entretanto, basta a mínima justificativa para que o Estado disponha e mobilize o que tem mais de ostensivo para inflamar a militarização das cidades, de forma que, fique claro quem ainda possui o monopólio legítimo da violência. Portanto, torna-se indistinguível o que são as operações locais e operações nacionais, ou seja, como se configura o interno e externo, considerando quem são os inimigos, se de fato é uma guerra ou trata-se de um policiamento recorrente. Neste sentido, é difícil estabelecer a diferença entre medidas militarizadas que visam o externo ou interno espacial do Estado-Nação, pois o que antes eram ferramentas de uso em casos excepcionais de cunho nacional é transferido para práticas corriqueiras em escalas cotidianas da cidade.

17 Ao concluir esta transferência, práticas de guerras são traduzidas em policiamento e controle social dos indesejados da cidade. "Há uma convergência expressiva de doutrina militar e tecnologias, satélite high-tech e drones desenvolvidos para monitorar inimigos da distante Guerra Fria ou insurgentes, estão sendo cada vez mais usados dentro das cidades ocidentais" (GRAHAM, 2016, p. 30). É exatamente nesta perspectiva que o Rio de Janeiro se aproxima desta lógica.

18 Ainda examinando Cidades Sitiadas de Stephen Grahan, o autor desta importante obra argumenta ser necessário assimilar, além do conceito de bumerangue do Foucault mencionado acima, outros quatros eixos principais do que ele mesmo chama de um novo urbanismo militar. O primeiro refere-se à urbanização da segurança em que técnicas militarizadas precisam ter um alcance minucioso e permanente da vida urbana tanto em espaços amplos quanto na escala da vida cotidiana. Como exemplo, aparecem o controle das redes de transporte coletivo com seguranças portando armas não-letais e câmeras espalhadas por toda malha de trafego. Como segundo eixo, segue o debate sobre economia política do urbanismo militar. Trata-se dos mercados possíveis alcançados pelo pensamento militarizante, assim não apenas armas de ponta e tecnologias são vendidas e exportadas mundo a fora, mas ideias e práticas já testadas em territórios ocupados, um tipo de campo prisional a céu aberto dentro do centro urbano. Por conseguinte, ressalta-se o aspecto de disputa da infraestrutura urbana tanto pelas forças de segurança do Estado como pelos grupos armados não estatais. Como exemplo, cita os grupos terroristas que utilizam estações de metrô como ameaça ao país atacado; aviões, caminhões de grande porte em locais de grande concentração no centro urbano. Por fim, chama atenção para formação de "Soldados-cidadãos". Este, trata-se não somente da transferência de armas de uso de guerra para vida civil como também a lógica comportamental militar para o cotidiano. Como exemplo, cita o uso do GPS, o entretenimento eletrônico e midiático, rede social, etc. Tudo isso, segundo o 
autor, suscita um tipo de comportamento militarizado popular e generalizado solapando as nítidas demarcações entre a esfera civil e militar. Conforme veremos adiante, algo muito característico no perfil do agente do Programa Segurança Presente.

Voltando para o Rio de Janeiro, cabe reforçar certas peculiaridades recorrentes na cidade carioca que remetem a militarização do espaço, como por exemplo, a atuação dos grupos armados como o varejo do tráfico e as milícias. Estes são responsáveis pelo controle armado, rigoroso e ostensivo com domínio territorial nas favelas e bairros periféricos com uso de violência direta. $O$ varejo do tráfico desde a década de 1970 vem atuando na cidade, principalmente no comércio de drogas em que facções disputam entre elas o monopólio dos pontos de venda. Comando Vermelho, Terceiro Comando Puro e ADA (Amigos dos Amigos) há anos que usam práticas de guerra militares com grande poder bélico na tentativa de eliminar o rival para assim assumir por completo a gerência dos negócios da venda de drogas. Já a milícia surge em bairros da Zona Oeste do Rio de Janeiro sob justificativa de levar segurança e proteção para os moradores dos bairros. 0 discurso norteador era trazer segurança para evitar que as facções do varejo de drogas chegassem até as populações destes bairros. Esse grupo majoritariamente é formado por policiais e ex-policiais, militares e ex-militares, civis e até mesmo extraficantes. Incialmente, os milicianos ao se estabelecerem territorialmente começam a explorar atividades econômicas como serviço de abastecimento de gás e água, serviço de transportes através de Vans e serviço de TV por assinatura, o chamado Gatonet. Desde a década de 1990 que este grupo armado vem ampliando seu poder e expansão territorial pela cidade. Além disso, suas atividades econômicas também se ampliaram chegando no ramo imobiliário, construção civil, grilagem de terras, cobrança de taxa pelo serviço de segurança e taxa para qualquer ocupação em algum serviço realizado por qualquer pessoa que precise sobreviver diante do colossal desemprego.

Nesse sentido, não poderia deixar de mencionar as operações das Forças de Segurança do estado (policias civil e militares), das quais carregam todos os aspectos da militarização do espaço urbano no Rio de Janeiro. Estas operações têm seu marco simbólico no início da década de 1990 cujo seu extremo culminaria nas Operações Rio I e II, o propósito da intensificação das operações reside no fato do novo tratamento dado as classes perigosas que agora são vistas como a inimiga a ser eliminada, portanto, as operações das forças de segurança se utilizam de uma lógica de guerra contra “inimigos" dentro do próprio território, as classes perigosas. Esta guerra travada pelo Estado através do seu braço armado, que já dura há anos, esteve lastreada na Guerra às Drogas. Durante todos estes anos, a guerra às drogas tornou-se a quase única explicação para todo aparato bélico e a produção de mortos resultantes das operações das forças de segurança. No entanto, é possível notar um caráter racial e higienista contra os pobres da cidade. Este ponto é importante para destacar a diferentes maneiras que o Estado encontra para perpetuar o controle social através da militarização. Portanto, o projeto segurança presente é o nexo militarizante a ser destacado neste trabalho.

\section{O Projeto Segurança Presente segue a ampliação da Militarização da Cidade do Rio de Janeiro}

21 O projeto Segurança Presente se inicia no ano de 2014, no bairro da Lapa, região central da cidade do Rio de Janeiro. Esta primeira experiência é resultado de um grito de desespero tanto da população em geral, mas também da imprensa e empresários para 
que fossem tomadas medidas contra o que seria o aumento da criminalidade na cidade. Este grito recebe eco após a drástica morte de um rapaz à facadas em 2013. Conrado Chaves da Paz, de 19 anos $^{4}$, supostamente, vítima de um usuário de crack, que trafegava pela Lapa. Este fato acontece em meio às críticas ao Governo de Sérgio Cabral e a já anunciada crise do estado pelas suas insuficiências administrativas e fiscais e mais as sistemáticas denúncias de corrupção pelas obras dos Megaeventos associadas ao então governador. Além da morte do jovem Conrado num contexto de movimentação política e social, Sérgio Cabral já era alvo de manifestações pela tortura e sumiço do pedreiro Amarildo por policiais da UPP da Rocinha, também em 2013. Muito embora, este momento era visto pela opinião pública o quanto as Unidades de Polícia Pacificadora estavam sendo um sucesso. Para eles, as UPP's eram uma novidade na política de segurança do Rio, principalmente no aspecto de policiamento de proximidade. Em 2013, quatro anos após a instalação da primeira UPP, no morro Dona Marta, a cidade recebia a instalação de mais quatro UPP's (nas favelas do Complexo do Lins, Manguinhos, Jacarezinho e Mandela), porém, os índices de violência não se reduziam, era preciso aprofundar os investimentos em Segurança Pública de forma generalizada, principalmente em bairros tradicionais e alguns de classe média. Neste momento, o Rio já contava com mais de 28 UPP's instaladas em favelas da Zona Sul da Cidade, mas também na Zona Norte e Centro. Em 2014, foi a vez da favela da Maré receber mais uma unidade de policiamento comunitário. Para as Forças de Segurança do Estado era região estratégica, pois é cortada tanto pelas Linhas Vermelha e Amarela, quanto pela Avenida Brasil, principais vias da cidade, e o Aeroporto Tom Jobim. Nesta operação para a criação de uma Unidade de Polícia Pacificadora, ocorre todo o espetáculo de sempre, como uma bandeira do Brasil sendo hasteadas simbolizando a "retomada territorial" pelas Forças de Segurança do Estado 5 . Cabe ressaltar que, em 2014 era ano de realização da Copa do Mundo no Brasil, portanto, fazia parte do gerenciamento urbano o cauteloso olhar, com a segurança, para tanto todas as medidas necessárias para garantir a tranquilidade da realização do megaevento esportivo seriam tomadas.

Nesse sentido é que, o projeto de Operação Segurança Presente começa a ser planejado e posto em prática e o bairro que primeiro irá receber é exatamente o bairro da Lapa. Inaugurado em janeiro de 2014 pelo então Governador Luís Fernando Pezão, a Operação contava com 95 agentes ao todo, tanto policias militares quanto agentes civis, fariam a segurança do bairro boêmio de bicicleta, em viaturas e até mesmo a pé, de quinta-feira à domingo. No caso dos policiais militares, estes trabalhariam nos seus dias de folga e os civis eram os praças dispensados do serviço obrigatório das Forças Armadas. Tal fato figura um sintoma grave da militarização: a confluência do comportamento civil com o militar para as relações sociais cotidianas. Completamente ignorado este sintoma, o objetivo do programa da Secretaria de Segurança era repetir o "sucesso" da polícia de proximidade realizada pelas UPP's. De início, rapidamente, alguns resultados imediatos são alcançados, segundo a própria Secretaria de Segurança, em 2014 após a implementação da Operação, 5.473 pessoas foram presas em flagrante na Lapa, 547 delas por roubo e furto. Além disso, 672 foragidos da Justiça foram capturados no bairro e houve mais de 37 mil ações de acolhimento a moradores de rua no período, com apoio da Secretaria Municipal de Desenvolvimento Social ${ }^{7}$. Nota-se, ao mesmo tempo, a simbiose entre projeto de segurança militarizado com a higienização do espaço urbano, em que os pobres são expulsos das áreas especuladas para atender o que era visto pelo poder público estadual uma oportunidade de revitalização urbana. Para a opinião pública e um olhar carente de análise, a Operação Lapa Presente tinha 
sido uma brilhantura única, ou seja, "até que enfim algo deu certo" referente às ações do estado Fluminense acerca da Segurança Pública, o desfecho era tão coroado com ares triunfantes, que urge a necessidade de expandi-lo para outros bairros onde índices de criminalidades e as reclamações por mais segurança eram pulsantes. $O$ deleite era tanto que chamou a atenção da Prefeitura, do Sesc, Fecomércio e Senac.

O vislumbre com a Operação Segurança Presente na Lapa transbordava de tal forma que apontava numa única direção: a multiplicação do projeto para outros bairros. $\mathrm{O}$ que de fato ocorre. No entanto, o governo do estado do Rio de Janeiro já não aparentava mais aquele sossego econômico e político de outrora, era necessário, portanto, buscar parceiras para a manutenção do sucesso do programa de segurança. Incentivado pelo Lapa Presente, Lagoa, Flamengo e algumas ruas do Méier receberão o programa Segurança Presente.

24 A expansão da Operação Presente para esses bairros ocorre em 2015 e é consequência da constituição de uma parceria pública e privada. Um traço característico do neoliberalismo de capitalismo tardio: entregar para iniciativa privada serviços públicos desde que os custos se restrinjam ao Estado ou que seus recursos estejam disponíveis para interesses privados. Portanto, o tema da Segurança Pública é caso de particulares e não da administração pública da cidade. Inicialmente, a Fecomércio (Federação do Comércio do Estado do Rio) se responsabilizaria em financiar por dois anos um projeto de segurança para reforçar o policiamento nesta microrregião. Nesse momento, irão compor o quadro de agentes 363 policiais da reserva ${ }^{8}$ e mais os dispensados do serviço obrigatório das Forças Armadas. Os salários e uniformes dos agentes também serão garantidos pela Fecomércio, enquanto que o governo do estado garantirá armas e viaturas. Quem também entra nessa parceria é a prefeitura do Rio, Agentes da Guarda Municipal, da Secretaria municipal de Desenvolvimento Social e Garis da Comlurb vão circular pelas regiões, podendo ser acionados para abordar ambulantes sem licença, menores em situação de risco ou retirar lixo acumulado. Desta forma, fica indubitável que o projeto de Segurança Presente assim como a Segurança Pública do Rio de janeiro também possui traços higienista e racista. Visto que, o projeto de cidade-empresa ou empreendedorismo urbano ora em curso na cidade do Rio de Janeiro era destoante com a presença dos indesejados da cidade, nas palavras do presidente da Fecomércio: "O objetivo é colaborar para aumentar a sensação de segurança do cidadão. A segurança é, claramente, um dos principais fatores para ajudar o Rio de Janeiro a continuar na vanguarda do desenvolvimento. Para nós, está na hora de entidades e empresários tomarem parte das soluções e não apenas apontarem problemas"".

Como era de se imaginar, a Operação Segurança Presente nos bairros do Aterro do Flamengo, Lago Rodrigo de Freitas e Méier, também rapidamente trouxeram a reivindicada sensação de segurança. Eficazmente os agentes conseguiram evitar alguns furtos, apreender algumas armas brancas, como facas por exemplo, e evitar o consumo de drogas ilícitas, além é claro, a remoção de pessoas em situação de rua, flanelinhas e ambulantes. Algo recorrente para os envolvidos no programa. O êxito agora do Programa Segurança Presente ultrapassava a "produtividade" dos agentes alcançando a parceria público-privado, portanto, à medida que se projetava a ampliação do programa, automaticamente, considerava-se o sucesso da parceria entre governo do estado, prefeitura e Fecomércio. Por conseguinte, era a expectativa para o próximo passo para outro local, sendo assim, o centro do Rio de Janeiro e sua Região Portuária seriam as próximas experiências das Operações Segurança Presente. Vale destacar que 
esta região já contava com o policiamento da UPP do morro da Providência. É nesse contexto que em 2016 o Centro do Rio recebia o programa da Secretaria de Segurança do estado do Rio de Janeiro, o centro presente.

Responsável por fazer a segurança de uma área de $133 \mathrm{mil} \mathrm{m}^{2}$, abrangendo os bairros da Gamboa, Saúde, Santo Cristo, parte da área do Centro do Rio e o Porto Maravilha, as justificativas para a implementação da Operação eram as mesmas precedentes das experiências anteriores: aumento dos assaltos, roubos de celulares, moradores de rua e falta de policiamento ostensivo. Os interesses também se confundiam entre público e privado, assim dizia o presidente da Fecomércio em reunião com representantes do governo do estado e da prefeitura:

O segmento empresarial está se mostrando mais próximo do cidadão comum, acompanhando suas necessidades diárias. Por isso, nossa missão é fornecer os recursos financeiros necessários para a implantação e manutenção das operações. 0 sucesso deste trabalho é fundamental para manter os investimentos das empresas na cidade e atrair novos. Mantendo-se os investimentos, quem ganha é a sociedade. Estamos falando de uma ação de longo prazo com foco muito objetivo. Esperamos inspirar grandes corporações para que apoiem a implantação desse projeto em outras regiões ${ }^{10}$.

Para realizar o policiamento em uma área tão extensa contando com o efetivo de 588 agentes entre policiais e civis, os organizadores do Centro Presente dividiram a área total em áreas A, B e C. Desta forma, na área A contaria com o total de 168 agentes, seu patrulhamento seria da recém-inaugurada Orla da Guanabara Prefeito Luiz Paulo Conde, na Região Portuária, a partir da Rua Silvino Montenegro, Avenida Venezuela, Praça Mauá, Avenida Rio Branco (até a Avenida Presidente Vargas), Candelária e entorno do $1^{\text {o }}$ Distrito Naval. A área B teria 216 agentes cuja incumbência de patrulhamento seria nas quadras do entorno da Av. Rio Branco, a partir da Avenida Presidente Vargas até a Avenida Nilo Peçanha, incluindo as ruas da Assembleia e São José, Uruguaiana, Largo do Paço, entorno do Tribunal de Justiça e Praça 15. Já a Área C, com 144 agentes, faria o policiamento Entorno do trecho da Avenida Rio Branco, a partir da Avenida Nilo Peçanha até a Avenida Beira-Mar, Rua México, Avenida Graça Aranha, Largo da Carioca, Cinelândia, Rua Senador Dantas (até o Passeio Público), Rua Santa Luzia, Avenida Presidente Wilson e Avenida Beira-Mar (do Monumento dos Pracinhas até o entorno do Aeroporto Santos Dumont) ${ }^{11}$.

Os projetos Lapa Presente, Centro Presente, Lagoa, Aterro e Méier Presente, em um intervalo curto, são as primeiras experiências que obtiveram respaldo positivo frente à opinião pública de modo geral. Apenas o Lapa Presente era custeado exclusivamente pela secretaria de segurança do estado do Rio de janeiro, os outros constituíam parcerias oficiais entre o poder público e a iniciativa privada. Estes exemplos também são os que serviram de referências para implementação em outros bairros e mesmo em outros municípios. Contudo, as crises econômicas e sociais assumem proporções alarmantes atingindo o programa que encontra uma profunda crise, correndo o risco de ser cancelado.

\section{O Governo de Wilson Witzel}

O contrato firmado entre a Fecomércio (incluindo Sesc e Senac), prefeitura e governo do estado, estabelecia a duração de dois anos de serviços executados, juntamente com a divisão das despesas e custos. Entretanto, antes mesmo do fim do prazo os sinais da 
crise já eram vistos. Agentes já questionavam a falta de pagamento. Críticas ao perfil dos agentes por parecerem com integrantes de milícia, também se ampliavam.

Ao todo Operação já contava com mais de 900 policiais envolvidos no patrulhamento nas áreas destinadas ao programa, estes policiais que cumpriam expediente pelo programa nos dias de folga recebiam 185 reais por dia trabalhado. Enquanto os civis, recebiam 2.400 reais de salário e mais 700 reais como ajuda de custo para cumprir o trabalho de policiamento. Diante do momento sensível do projeto, a prefeitura, já na gestão do Bispo Marcelo Crivella, indicava a suspensão da Operação como forma de "redução dos gastos da prefeitura. ${ }^{12 " O}$ Bispo chegou mesmo a cogitar a substituição do Programa Operação Segurança Presente pelo "Rio mais Seguro", da própria prefeitura ${ }^{13}$. O projeto Segurança Presente já era executado em 11 bairros na capital e mais em dois municípios, Nova Iguaçu e Niterói, portanto a retórica do Bispo salta aos olhos por conta de sua incoerência argumentativa. Se sua intenção era suspender o programa como tentativa de redução de custos por que então a alternativa oferecida foi juntar a outro projeto da prefeitura, sem parceria com iniciativa privada aumentando os custos? Esta "crise" apenas comprova que o projeto de Segurança Presente é um mero paliativo atrelado ao que significa no Rio de Janeiro de Segurança Pública. Além de revelar a precariedade do contrato de trabalho para quem exercia a função de agente do programa.

31 A incerteza quanto a permanência ou não do Programa Segurança Presente só será sanada com as eleições de 2018 e, consequentemente com a eleição para Governo do Estado Wilson Witzel do PSC. É no seu mandato que o Segurança Presente ganha folego permitindo sua permanência por mais um período, ao mesmo tempo em que amplia para outros bairros, agora da periferia.

Wilson Witizel foi eleito Governador do estado do Rio de Janeiro em uma eleição que até a semana precedente ao pleito parecia improvável. Witzel apresentava apenas $2 \%$ das intenções de voto no início da campanha, chegando a $39 \%$ pouco antes da votação, passando até mesmo o favorito para eleição daquele ano, o ex prefeito Eduardo Paes $(\mathrm{MDB})^{14}$.

Wilson Witzel mesmo antes de ser eleito já anunciava que sua gestão de governo seria uma completa caça aos pobres e favelados sob a justificativa de combate ao crime organizado. A prioridade do seu governo não seria, portanto, as áreas mais cruciais para a população em geral, como infraestrutura urbana, transporte, saúde e educação públicas. Witzel, a todo momento anunciava que sua prioridade de governo seria a segurança pública, ou seja, intensificar a política de extermínio permanente nas favelas cariocas. Conforme ele mesmo afirma: "a polícia vai mirar na cabecinha...fogo! " (Jornal O Estadão $1 / 11 / 2018)^{15}$. É importante ressaltar que, este comentário do governador não é algo destoante do contexto social da cidade maravilhosa. Basta lembrar que 2018 foi o ano de intervenção federal na cidade por um período de 10 meses a segurança da cidade era responsabilidade das Forças Armadas.

Já nos primeiros oito meses de 2019 ocorre o aumento da letalidade policial em operações com 1.249 mortes entre janeiro e agosto, uma média de 5 mortes por dia! ${ }^{16} \mathrm{E}$ não parava apenas na produção de mortes, o governador fazia questão de mostrar afinidade com a polícia militar, fosse aparecendo em fotos com policiais do Bope fazendo flexão no quartel, fosse segurando uma metralhadora ponto $30 \mathrm{em}$ coletiva de imprensa após uma operação do Bope no Complexo do Alemão ${ }^{17}$. Wilson Witzel é a expressão da estatização das mortes via militarização via Forças de Segurança como a 
Polícia Militar. Nesse cenário, é que Wilson Witzel volta-se para o programa Segurança Presente, na tentativa de resolver a ameaça de término das operações. Foi em novembro de 2019 que Witzel anunciava/confirmava não somente a permanência do programa, mas a inauguração da $17^{\mathrm{a}}$ base do Segurança Presente, só que agora, na Barra da Tijuca, na Zona Oeste do Rio de Janeiro, que já contava com uma base em Jacarepaguá, com o investimento de 18 milhões por ano do governo. Além do mais, o astucio governador para esta fase do projeto, consegue firmar uma parceria com o grupo Multiplan, grupo que administra o Barra Shopping e o Village Mall, ambos realizaram a doação dos equipamentos que seriam utilizados pelos agentes. Foram

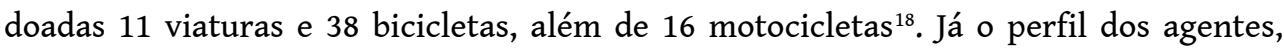
corresponde aos mesmos das experiências anteriores, policiais militares e civis dispensados pelas Forças Armadas.

o caso mais atípico é da Operação Presente do bairro de Irajá, inaugurado recentemente. Ao invés de recrutar egresso das Forças Armadas, o governo se junta ao processo de alistamento obrigatório e contrata os jovens que sobraram para serem agentes do Segurança Presente! Ou seja, jovens que acabam de completar 18 anos de idade, na visão de Wilson Witzel teriam a capacidade de contribuir para diminuir as taxas violência no bairro. A justificativa possível pelo governo era que o treinamento para estes jovens seria oferecido pelo Senac e o Sesc ${ }^{19}$. Pode-se admitir, conforme mencionamos acima, que este fato converge com os "Soldados-cidadãos" tratados por Stephen Graham em "Cidades Sitiadas".

36 Nesse sentido, é que esta forma de policiamento urbano vai se padronizando aos poucos pelas mãos de Witzel. Por um lado, a intensificação as operações policiais em favelas com uso de helicópteros e produção de mortes, por outro, a ampliação do programa Segurança Presente para outros bairros através de parcerias com empresários locais. É uma forma também de institucionalizar algo que já era corriqueiro no policiamento na cidade do Rio de Janeiro. Para que um comerciante e empresário local tivesse um policiamento efetivo teria que realizar pagamento ilícito diretamente aos policiais de serviço ou aos superiores das delegacias. Por exemplo, no Segurança Presente Tijuca são os comerciantes locais quem firmam acordo com o governo, o mesmo acontece em Jacarepaguá, é a Associação Comercial e Industrial de Jacarepaguá quem financia o projeto $^{20}$. É desta forma que outros bairros vão recebendo a Operação Segurança Presente.

\section{Conclusão}

37 O objetivo deste trabalho foi relacionar o Programa Segurança Presente do Governo do estado do Rio de Janeiro e empresários com o processo de militarização do espaço urbano. Hoje, o projeto possui 27 bases em todo estado (Caxias, Nova Iguaçu, São Gonçalo, Niterói e Rio de Janeiro e São João de Meriti) contando com a capital carioca. São mais de 2000 agentes envolvidos no programa entre policiais militares de folga e civis. O que aparece como novidade, com o tempo, na realidade manifesta mais do mesmo de anos anteriores, portanto, nenhuma solução à vista sobre a questão da violência urbana, porém vemos sim, a ampliação da militarização do espaço urbano muito por causa de sua expansão geográfica. Infelizmente, nesta ocasião não conseguimos dar conta de todos os bairros que receberam o programa de forma pormenorizada e territorializada, no entanto, ao longo deste trabalho tentamos 
estabelecer um panorama do significado social do Projeto Segurança Presente nos contextos da Segurança Pública e militarização das cidades.

Tanto a Segurança Pública quanto a militarização do espaço urbano orientada pelo Estado possuem o propósito de controle e extermínio das classes perigosas. Esta tem sido a única diretriz quanto à "soluções" para a questão da violência na cidade.

\section{BIBLIOGRAFIA}

ALEXANDER, Michelle. A Nova Segregação: racismo e encarceramento em massa. Editora Boitempo: São Paulo, 2017.

GRAHAN, Stephen. Cidades Sitiadas: o novo urbanismo militar. Editora Boitempo. São Paulo, 2016 GUIMARÃES, Alberto. As Classes Perigosas. Editora Graal. Rio de Janeiro, 1982.

MBEMBE, Achille. Crítica da Razão Negra. Editora N-1 Edições. São Paulo, 2018.

MENGAT, Marildo. A Crítica do Capitalismo em Tempos de Catástrofe: o giro dos ponteiros do relógio no pulso de um morto. Editora Consequência. Rio de Janeiro, 2019.

WACQUANT, Loic. A Estigmatização Territorial na Idade da Marginalidade Avançada. Artigo. disponível em: http://ler.letras.up.pt/uploads/ficheiros/4618.pdf

WACQUANT, Loic. As duas Faces do Gueto. Editora Zahar. São Paulo, 2011.

ZAVERUCHA, Jorge. "Relações Civil-Militares: o legado autoritário da constituição brasileira de 1988." In: “O que Resta da Ditadura.” Orgs. TELES, Edson; SAFATLE, Vladimir. Editora Boitempo. São Paulo, 2010.

\section{Artigos de Jornal Diário}

BRITO, Carlos. Witzel Anuncia a Contratação de Dois Milil Jovens para o Programa Segurança Presente. G1 Site de Notícias, Rio de Janeiro, 17 Fev, 2020. G1- Rio de Janeiro.

CARVALHO, Janaína. Conjunto de Favelas da Maré é ocupado para instalação de UPP. G1 sites de notícia, Rio de Janeiro, 30 Mar, 2014.

CONSTANCIO, Thaise. Pezão assume governo do Rio e exalta realizações de Cabral. Jornal Estadão, São Paulo, 4 Abril, 2014. Estadão Online.

DAVID, Flávia. Operação Centro Presente terá mais de 500 Agentes e Beneficiará Áreas Revitalizadas da Cidade. Boletim da Prefeitura do Rio de Janeiro, Rio de Janeiro, 31 Maio, 2016. Visitado em: 04/03/2020.

G1 SITE DE NOTÍCIAS. Agentes do programa Segurança Presente estão há dois meses sem receber no Rio. Rio de Janeiro, 06 Jun, 2018. Visitado em: 01/03/2020.

GANDRA, Alandra. Governo do RJ diz que operação na Lapa reduziu 70\% dos roubos na região. Agencia Brasil, Rio de Janeiro, 01 Jan, 2018. Repórter Agência Brasil-Rio de Janeiro.

JORNAL EXTRA. Empunhando metralhadora, Witzel posa com armas apreendidas no Complexo do Alemão. Extra Online, Rio de Janeiro, 30 Maio, 2019. Casos de Polícia. Visitado em 11/03/2020. 
JORNAL NACIONAL. No Rio, número de mortes por policiais em 2019 é recorde. G1 site de Notícias, Rio de Janeiro, 20 Set, 2019. Visitado em: 10/03/2020.

MAGALHÃES, Luiz Ernesto. Lagoa, Aterro e Méier precisarão policiais pagos pela Fecomércio. Jorna O Globo, Rio de Janeiro, 24 Out, 2015. Globo Online.

NOTÍCIAS UOL. Pesquisa boca de urna no RJ: Wilson Witzel tem 39\%, Paes $21 \%$ e Tarcísio 15\%. São Paulo, 07 Jul, 2018. Visitado em 07/03/2020.

PENNAFORT, Roberta. A polícia vai mirar na cabecinha e ... fogo', diz novo governador do Rio. Jornal Estadão, São Paulo, 01 Nov, 2018. Estadão Online.

RODRIGUES, Renan. Witzel Anuncia Expansão do Programa Segurança Presente para o RecreioVisitado. Jornal o Globo, Rio de Janeiro, 29 Nov, 2019. O Globo online.

VIÊGAS, Giuliane. Gêmeo lamenta morte de jovem encontrado no Centro do Rio: 'Eu me enxergava nele'. Jornal Extra, Rio de Janeiro, 12 Jan, 2013. Extra Online.

\section{NOTAS}

1. Grifo nosso.

2. Para ficar apenas neste exemplo, em 2014, a presidente Dilma Rousself assinou o decreto autorizando o uso das Forças Armadas sustentadas através da GLO, Garantia da Lei e a da Ordem pelos militares. A GLO ocorre oficialmente nos casos em que há esgotamento das forças de segurança, como as polícias civil e militar e assumem a incapacidade de manutenção da ordem social estabelecida. A primeira experiência de aplicação da GLO foi na favela da Maré, na Zona Norte da cidade do Rio de Janeiro.

3. Ver: ZAVERUCHA, Jorge. "Relações Civil-Militares: o legado autoritário da constituição brasileira de 1988." In: "O que Resta da Ditadura." Orgs. TELES, Edson; SAFATLE, Vladimir. Editora Boitempo. São Paulo, 2010.

4. Disponível em: https://extra.globo.com/casos-de-policia/gemeo-lamenta-morte-de-jovemencontrado-no-centro-do-rio-eu-me-enxergava-nele-10936553.html,

5. http://g1.globo.com/rio-de-janeiro/noticia/2014/03/conjunto-de-favelas-da-mare-e-ocupadopara-instalacao-de-upp.html

6. "O vice-governador Luiz Fernando Pezão do PMDB assumiu como governador do Rio e declarou que vai continuar o trabalho do ex-governador Sérgio Cabral também do PMDB. Na cerimônia realizada na Assembleia Legislativa do Rio de Janeiro (Alerj), o Pezão disse que seus principais desafios têm uma política de segurança pública com as Unidades de Polícia Pacificadora - UPP”. Disponível em: https://politica.estadao.com.br/noticias/geral,pezao-assume-governo-do-rio-eexalta-realizacoes-de-cabral,1149374

7. http://agenciabrasil.ebc.com.br/geral/noticia/2018-01/governo-do-rj-diz-que-operacao-nalapa-reduziu-70-dos-roubos-na-regiao

8. Não ficou claro o perfil deste policial da "reserva", que vai desde o policial aposentado por tempo de serviço até aquele afastado por processo administrativo ou que havia sido expulso. Não é exagero associar que este perfil se enquadra com o perfil de integrantes da milícia.

9. Disponível em: http://oglobo.globo.com/rio/lagoa-aterro-meier-terao-policiais-pagos-pelafecomercio-17868090

10. Disponível em: http://www.rio.rj.gov.br/web/guest/exibeconteudo?id=6167059. Visitado em: 04/03/2020.

11. IDEM 
12. https://g1.globo.com/rj/rio-de-janeiro/noticia/agentes-do-programa-seguranca-presenteestao-sem-receber-salarios-no-rio.ghtml

13. O RIO+SEGURO é um programa pioneiro da Prefeitura do Rio de Janeiro, que associa planejamento, inteligência e tecnologia na prevenção à desordem urbana e à criminalidade. A iniciativa começa pelos bairros de Copacabana e Leme, cartões postais da Cidade Maravilhosa e envolve a Guarda Municipal, Cet-Rio, Rio Luz, Secretaria Municipal de Conservação e Meio Ambiente (Seconserma), Riotur, Comlurb, Secretaria Municipal de Assistência Social e de Direitos Humanos (SMASDH), Coordenadoria de Gestão do Espaço Urbano (CGEU) e a Superintendência da Zona Sul. A Secretaria de Ordem Pública (SEOP) coordena a operação. http://maisseguro.rio/ Visitado em: 01/03/2020.

14. https://noticias.uol.com.br/politica/eleicoes/2018/noticias/2018/10/07/boca-de-urnapesquisa-ibope-rio.htm

15. https://politica.estadao.com.br/noticias/eleicoes,a-policia-vai-mirar-na-cabecinha-e-fogodiz-novo-governador-do-rio,70002578109

16. https://g1.globo.com/jornal-nacional/noticia/2019/09/20/no-rio-numero-de-mortes-porpoliciais-em-2019-e-recorde.ghtml

17. https://extra.globo.com/casos-de-policia/empunhando-metralhadora-witzel-posa-comarmas-apreendidas-no-complexo-do-alemao-23633081.html

18. https://oglobo.globo.com/rio/witzel-anuncia-expansao-do-programa-seguranca-presentepara-recreio-24108742

19. https://g1.globo.com/rj/rio-de-janeiro/noticia/2020/02/17/witzel-anuncia-contratacao-dedois-mil-jovens-para-o-programa-seguranca-presente.ghtml

20. https://extra.globo.com/casos-de-policia/seguranca-presente-vai-ser-levado-parajacarepagua-maracana-bancado-por-comerciantes-23388067.html

\section{RESUMOS}

O objetivo deste trabalho é demonstrar o avanço da militarização do espaço urbano através do Programa Segurança Presente da cidade do Rio de Janeiro. Em tempos de crise das UPPs, fica claro que, expansão geográfica do Programa Segurança Presente atesta, junto com as Operações Policias, o policiamento urbano realizado pelas Forças Armadas e o domínio territorial dos grupos armados como as milícias e as facções do varejo do tráfico, as formas marcantes da militarização do espaço urbano do Rio de Janeiro. Desta forma, realizaremos diálogos teóricoconceituais com diversos autores da temática tanto da militarização quanto sobre a crise estrutural do capitalismo e principalmente conteúdo jornalístico do tempo presente.

The objective of this work is to demonstrate the advancement of the militarization of the urban space through the Present Security Program in the city of Rio de Janeiro. In times of crisis for the UPPs, it is clear that, along with the present security program's geographical expansion, together with the Police Operations, it attests to the urban policing carried out by the Armed Forces and the territorial dominance of armed groups such as the militias and the retail factions of the drug trade, the striking forms of militarization of the urban space of Rio de Janeiro. In this way, we will carry out theoretical-conceptual dialogues with various authors on the theme of both militarization and the structural crisis of capitalism and mainly journalistic content of the present time. 
L'objectif de ce travail est de démontrer l'avancement de la militarisation de l'espace urbain à travers le programme de sécurité actuel dans la ville de Rio de Janeiro. En période de crise pour les UPP, il est clair que, parallèlement à l'expansion géographique du programme de sécurité actuel, ateste, avec les opérations de police, il témoigne de la police urbaine exercée par les forces armées et de la domination territoriale de groupes armés tels que les milices et les factions de détail du trafic de drogue, les formes marquantes de militarisation de l'espace urbain de Rio de Janeiro. De cette façon, nous allons mener des dialogues théorico-conceptuels avec différents auteurs sur le thème à la fois de la militarisation et de la crise structurelle du capitalisme et principalement du contenu journalistique de l'époque actuelle.

El objetivo de este trabajo es demostrar el avance de la militarización del espacio urbano a través del Programa de Seguridad Actual en la ciudad de Río de Janeiro. En tiempos de crisis para las UPP, es evidente que, junto con la expansión geográfica del actual programa de seguridad, junto con los Operativos Policiales, da fe de la vigilancia urbana que realizan las Fuerzas Armadas y del dominio territorial de grupos armados como las milicias y las facciones minoristas del narcotráfico, las llamativas formas de militarización del espacio urbano de Río de Janeiro. De esta manera, realizaremos diálogos teórico-conceptuales con diversos autores sobre el tema tanto de la militarización como de la crisis estructural del capitalismo y principalmente contenidos periodísticos de la actualidad.

\section{ÍNDICE}

Palavras-chave: Projeto Segurança Presente, militarização, espaço urbano, Rio de Janeiro.

Palabras claves: Proyecto Segurança Presente, militarización, espacio urbano, Río de Janeiro.

Keywords: Segurança Presente Project, militarization, urban space, Rio de Janeiro.

Mots-clés: Projet Segurança Presente, militarisation, espace urbain, Rio de Janeiro.

\section{AUTOR}

\section{THIAGO SARDINHA}

Doutorando em Ciências Sociais pelo Programa de Pós Graduação da UFRRJ. Professor de Geografia, Educador Popular no Projeto "Estudando para Vencer" no bairro da Vila Cruzeiro - RJ. E-mail: thiagogeorural@gmail.com. 